\title{
Genetic variation in foraging traits among inbred lines of a predatory mite
}

\author{
F Jia ${ }^{1}$, DC Margolies ${ }^{1}$, JE Boyer ${ }^{2}$ and RE Charlton ${ }^{1}$ \\ ${ }^{1}$ Department of Entomology, Kansas State University, Manhattan, KS 66506, USA; ${ }^{2}$ Department of Statistics, Kansas State \\ University, Manhattan, KS 66506, USA
}

Response of predators to herbivore-induced plant volatiles can affect the length of time a predator spends in a prey patch and the probability of a predator finding a new prey patch. Variation in response to herbivore-induced plant volatiles may lead to different foraging decisions among individuals, thereby affecting both within-patch dynamics and between-patch dispersal. We found significant phenotypic and additive genetic variation in two behavioral assays of response to herbivore-induced plant volatiles among inbred isofemale lines of the predatory mite, Phytoseiulus persimilis. In wind-tunnel tests to measure patch residence time, adult female predators from certain lines left prey patches sooner than others when a distant source of herbivoreinduced plant volatiles was presented; whereas such variation disappeared when no distant volatiles were presented. In a measure of patch location, certain lines were more likely than others to locate a prey-infested leaf disc; again there was no difference when uninfested leaf discs were used. Patch location was negatively correlated with patch resi- dence. That is, lines that were more likely to leave a prey patch in the presence of distant volatiles were also more likely to find an odor source (ie, prey patch) from a distance of $20 \mathrm{~cm}$. These two foraging-related behaviors are heritable. A continuous distribution of both behaviors indicated that several to many loci may be responsible for these behavioral traits. Our line-crossing experiments suggested that maternal influence could be excluded. Substantial phenotypic variation in two other foraging-related traits, consumption and oviposition, were also detected among inbred lines. Consumption and oviposition were positively correlated; however, the relationship (slope) varied among inbred lines, suggesting that predatory mites vary in food conversion efficiency. A relationship was detected between patch residence and consumption. Patch location, as one important foraging trait, appeared to be negatively related to consumption, suggesting a trade-off between searching for patches and reproduction.

Heredity (2002) 89, 371-379. doi:10.1038/sj.hdy.6800145

Keywords: Phytoseiulus persimilis; patch residence; patch location; foraging behaviors; consumption and oviposition; herbivore-induced plant volatiles

\section{Introduction}

Foraging efficiency of predators may depend on their ability to detect or respond to the presence of prey. Attraction to, or retention by, herbivore-induced plant chemicals may benefit the natural enemy searching for prey by increasing its ability to detect prey-infested plants. This seems to be true of the phytoseiid mite, Phytoseiulus persimilis (Athias-Henriot), a specialist predator on tetranychid mites, especially on the two-spotted spider mite, Tetranychus urticae Koch (Sabelis, 1985). Phytoseiulus persimilis is a voracious predator and can rapidly deplete local prey populations. On a small scale, $P$. persimilis may leave one prey patch and walk to another nearby after the depletion of prey. However, for prey depletion on a larger scale or in isolated patches, $P$. persimilis engages in long-distance dispersal, often as aerial plankton. After landing, these predators may take advantage of herbivore-induced plant volatiles and orient to nearby prey patches (Janssen, 1999); they can respond to

Correspondence: F Jia, Department of Entomology, Kansas State University, Manhattan, KS 66506, USA. E-mail: fjia@oznet.ksu.edu Received 6 December 2001; accepted 29 May 2002 wind-borne spider mite-induced plant volatiles over a distance of several meters (Sabelis and van der Weel, 1993). Once within a prey patch, a number of local factors can influence search behavior and residence times of $P$. persimilis. For example, the presence of chemical and physical signals from prey or their products, such as feces and webbing, in the immediate vicinity of the prey patch may delay when a predator leaves a patch (Sabelis, 1981; Maeda et al, 1999; Mayland et al, 2000). Residence time on a prey patch also may be increased by predator response to locally produced prey-induced plant volatiles. For example, predators that happen to walk out of an odor cloud frequently turn back to it (Sabelis et al, 1984). These responses keep a predator in proximity to its food.

Presumably, natural selection should favor predator genotypes that are best able to use the information on prey availability offered by herbivore-attacked plants (Price et al, 1980; Dicke and Sabelis, 1988, 1989). Assessing genetic variation in the response of natural enemies to plant-derived volatiles is the first step to understanding the role of this response in predator-prey dynamics (Dicke et al, 1990a, b; Lewis and Martin, 1990; Vet and Dicke, 1992). Documentation of genetic variation in foraging behavior is also important for understanding the 
process of evolution, and may be important for selection and application of natural enemies in biological control (Mackauer, 1976; Lewis and Martin, 1990; Hopper et al, 1993; Bruins et al, 1994). Genetic variation in components of search behavior has been reported in predatory arthropods and parasitoids (Hoy, 1990; Hopper et al, 1993; Bruins et al, 1994; Gu and Dorn, 2000). Previous studies on attraction of $P$. persimilis to volatiles produced by prey-infested lima bean plants suggested considerable phenotypic variation in predator responsiveness (Margolies et al, 1997). The additive genetic variation for the behavioral has been measured in an olfactometer (Margolies et al, 1997), although the involvement of maternal influence was not excluded. However, success, and presumably fitness, of a predator involves more than searching ability, and evidence of genetic variation in other related traits of $P$. persimilis is still rare.

Variability in sensitivity, or responsiveness, of predators to herbivore-induced plant volatiles may lead to different dispersal strategies, ultimately affecting predatorprey dynamics. Pels and Sabelis (1999) examined two geographic populations of $P$. persimilis and found that one (Enna) was more likely to disperse and leave a prey patch before the elimination of prey, whereas the other (Alcamo) had long residence times and almost no dispersal as long as there was prey available. This finding suggests the possibility of two different predator dispersal strategies, as proposed by Van Baalen and Sabelis (1995); one (a type they dubbed 'Killer') in which predators remain in a patch as long as there are prey left and the other (that they called 'Milker') in which predators disperse at a constant rate from a patch. The major objective of the present study was to examine genetic components of phenotypic variation in several, ecologically relevant foraging behaviors of the phytoseiid predator in the presence of lima bean volatiles in both wind-tunnel and still air conditions. To this end we used inbred isofemale lines. Inbred isofemale lines play an important role in assessing the nature of phenotypic variation in natural populations. Since each isofemale line is built up from a single female, one of the major advantages of using isofemale lines is that genetic information is measurable in species where details of the genome are not very clear (Parsons, 1980), as is the case with P. persimilis.

\section{Materials and methods}

\section{Bean plants}

Bean plants (Phaseolus lunatus L. cv. Sieva) served as host plants for spider mites in all experiments. Beans were grown in a greenhouse under $400 \mathrm{~W}$ high-pressure sodium vapor lamps on a L16:D8 photoperiod at 22$25^{\circ} \mathrm{C}$. All plants that were used had two fully expanded cotyledons but the first trifoliate leaves were not yet developed.

\section{Prey mites}

The T. urticae population we used was derived initially from a wild population found on soybeans in Garden City, KS, USA. It was maintained on lima bean plants in a rearing room under the same light and temperature as is typical for its host bean plants.

\section{Predatory mites ( $P$. persimilis)}

All experiments were conducted with $P$. persimilis originally obtained from a commercial supplier, Rincon-
Vitova, Ventura, CA, USA, in April 1999. Twenty-five inbred lines of $P$. persimilis were established and maintained under laboratory condition $\left(24^{\circ} \mathrm{C}, \mathrm{RH}=60-70 \%\right.$, L16:D8). Each line was started with a single, mated female and kept in a jar in an environmental chamber at $24^{\circ} \mathrm{C}$ and L16:D8 light cycle. Predatory mites were fed regularly with two-spotted spider mites on leaves of lima beans. Predatory mites were maintained in colony for more than 10 generations prior to this series of experiments. The lines used in these experiments were maintained with at least $50 \mathrm{P}$. persimilis in every line for each generation thereafter. Thus, it is likely that very little genetic variability was lost in the subsequent generations, and the inbred lines should reflect traits of the initial founders for many generations (Parsons, 1983).

Predator condition for tests was standardized by using only female predators whose last molt had occurred within the previous 3-7 days; previous testing showed stable and high consumption and oviposition among females in this age group (unpublished data). Predators selected for use were kept without food for $2 \mathrm{~h}$ immediately prior to testing; this should have been sufficient time to allow the gut to empty but not affect the basic searching behaviors (Sabelis, 1981). Because of the need to test many individuals from each line, and because not all lines had sufficient individuals available for testing at any given time, we did not examine the response of all 25 lines in each situation. Instead, we tested enough lines (between 11 and 18, depending on the assay) to provide a representative range of responses.

\section{Consumption and oviposition of predatory mites on leaf discs}

We examined the consumption and oviposition rates of 16 isofemale lines. One predator was chosen randomly from an inbred line and placed in a small vial $(2.5 \mathrm{~cm}$ diameter and $5.5 \mathrm{~cm}$ height) in which a small bean leaf disc (approximately $1 \mathrm{~cm}$ diameter) with about 50 oneday old prey eggs was provided. Then, the vial was sealed with parafilm and maintained in an environmental chamber $\left(24^{\circ} \mathrm{C}, \mathrm{RH}=60-70 \%\right.$, L16:D8) for $24 \mathrm{~h}$, after which the number of prey eggs left on the disc was counted. In addition, any predator eggs generated within the 24-h period were also counted. On average, 64 adult females were checked for each line; the minimum number of adult females examined was 30 and maximum 112 . Consumption rate was defined as the number of prey eggs consumed by a predatory mite within $24 \mathrm{~h}$ and the oviposition rate was defined as the number of eggs laid by a predator mite within $24 \mathrm{~h}$.

\section{Residency of predatory mites in wind-tunnel}

We assayed 18 inbred lines in wind-tunnel experiments to assess the influence of spider mite-induced plant volatiles on residency. Nine of these inbred lines were among those tested for oviposition and consumption. Patch residence was examined in four similar windtunnels, each 1.5 meters long, 0.5 meter wide and 0.25 meter high constructed with plexiglas sides and removable plexiglas lids. Two fume hoods drew air through two wind-tunnels each (wind speed $=3 \mathrm{~cm} / \mathrm{s} ; 24.5 \pm$ $0.5^{\circ} \mathrm{C} ; \mathrm{RH}=60 \%$ ). Five individually potted lima bean plants were placed in a line perpendicular to the airflow at the downwind end of the wind-tunnel. The distance between two neighboring pots was $10 \mathrm{~cm}$, sufficient to 
prevent contact between plants. The downwind bean plants had one cotyledon clipped off, leaving one remaining. A half flat $(\mathrm{L} 27 \mathrm{~cm} \times W 27 \mathrm{~cm} \times \mathrm{H} 5.5 \mathrm{~cm})$ of lima beans that was heavily infested by two-spotted spider mites was used as the source of external chemical volatiles. In the control situation, an uninfested half flat of lima beans was used. In either case the half flat was set up on the upwind end of the wind-tunnel, $80-\mathrm{cm}$ from the individual lima bean plants in the downwind end.

Six adult female spider mites were placed on the leaf of each downwind plant for a $24-\mathrm{h}$ period. Immediately before the predator release, all but 20 prey eggs with associated webbing were removed from the leaf. Five predatory mites, all from the same line, were then released on each bean plant. The number of predatory mites that stayed on the leaf was counted every hour for $4 \mathrm{~h}$. At the end of the fourth hour, we counted the number of prey eggs that remained. We calculated a residence index as the number of predatory mites that resided on the bean plant each hour, multiplied by the time (hours), summed over all hours subjected to the test. Thus, the larger the index, the more and longer mites stayed on a plant. The maximum value was $50(=5 \times 1$ $+5 \times 2+5 \times 3+5 \times 4)$ if all the predators stayed through the test.

\section{Patch location of predatory mites in arena}

We examined the prey-patch location abilities of 11 inbred lines, 10 of which were previously examined in the wind-tunnel tests. Variation among predatory mites in ability to locate the source of prey-related cues was examined on a $40 \mathrm{~cm}$ (diameter) circular surface in still air. The size of the arena was based on previous studies of plant location by adult female $P$. persimilis that indicated predators exhibited increased turning rates and decreased walking speed (ie, area-concentrated search) within $20-\mathrm{cm}$ of a prey-infested plant (Zemek and Nachman, 1998; Mayland, 1998). A sticky material (Insect Trap Coating, the Tanglefoot Company, MI, USA) encircling the arena prevented predators from leaving during the 10-min test. Two similar arenas were set up side-by-side with a vertical $(50 \mathrm{~cm} \times 30 \mathrm{~cm})$ cardboard divider between them to reduce air movement and volatile drift. To further reduce the influence of air movement on predator orientation and activity, the arenas were located in a small room $(3 \mathrm{~m} \times 1.2 \mathrm{~m})$ that was closed off when running a test. A 40-watt fluorescent circle-line light above the arenas provided illumination. Room temperature was maintained near $26.5^{\circ} \mathrm{C}$ and humidity at about $60 \%$. Tests were usually conducted from 1400 to 1500 hours.

For each repetition of the experiments, two leaf discs $(2.2 \mathrm{~cm}$ in diameter) were cut from the same, heavilyinfested leaf (ie, $80 \%$ of the leaf appeared heavily damaged after mites were allowed to feed for 4-5 days) and used in simultaneous tests, one in each arena. One disc was placed at the center of each arena on moist cotton wool to maintain the freshness of the disc during the experimental period. The leaf disc was placed in the arena $2 \mathrm{~h}$ prior to introducing the predators to permit enough time for volatiles to diffuse. In still air, the odor dispersion process is governed by molecular diffusion, and after two hours an odor sphere presumably formed around the disc on the arena (Mankin et al, 1980). We also ran two types of controls. For the first, procedural control, uninfested fresh leaf discs were used. This control was included to assess the role of the plant itself on predator behavior. In the second, blank control, neither leaf disc nor wet cotton were provided in the center of the arena. This control was designed to examine the rate at which the predators would reach the central area by chance alone.

Lines were run in pairs, one line on each arena, to account for variability due to the odor source disc. Specific pairings for each run of the experiment were determined by the experimental design described below and the availability of a sufficient number of adult female predatory mites in a line at a particular time. Ten young adult female predatory mites were picked from each of the paired lines and kept in an empty vial, one for each line, for two hours prior to being released at the edge of the arena. Each line was tested at least five times under each treatment (minimum of 50 mites per line per treatment). The surface of the arena was always cleaned between trials to minimize contamination between runs. We recorded patch location proportion (how many predatory mites were able to reach the central disc within the first $10 \mathrm{~min}$ ), patch location time (minutes:seconds to reach the central disc), and how many predatory mites remained on the disc at the end of experiment.

There were 11 lines used in these tests; we chose lines that represented the range of responses exhibited in the wind-tunnel tests and were available in sufficient numbers during the experimental period. It was not feasible to test all possible pairings of the 11 lines so a collection of 22 pairings was selected. The collection was designed so that if a particular pair of lines, say A and B, were not simultaneously available, then there was among the 11 lines of interest a third line, say C, such that A and C were run together and $B$ and $C$ were run together. Specifically, we used a Balanced Incomplete Block design in which the treatments were the lines and the blocks were the pairs of lines that were being compared. This design required block sizes of 2 , yet used all 11 treatments (lines), each of which were observed four times. Thus, we were able to deal with uncertainty in the availability of a given line at a specific time and to make the most efficient use of time given the large number of possible comparisons. It maximized, for the resources available, the 'connectedness' of the design.

\section{Crosses between inbred lines}

Inbreeding can increase the probability of an individual being a homozygote over time (Falconer and Mackay, 1996). This implies that variation among inbred lines is mostly genetic, whereas variation within lines may be attributed to common environmental effects. However, one major concern is that maternal effects may be involved in the difference among lines. To assess the importance of such maternal effects on the results from the inbred lines, line cross experiments were conducted between two pairs of lines of predatory mites maintained in the laboratory for more than 12 months, or over 20 generations at $24^{\circ} \mathrm{C}$. Their inbreeding coefficient may have approached 95\% (Falconer, 1983).

Two pairs of inbred lines were chosen from among lines based on their response in the arena assay. They were selected so that one line of each pair showed a stronger response (high-lines were 70 and 52) than the other line (low-lines were 73 and 65) in patch location 
ability. We wanted to pair lines that were as different as possible to maximize the likelihood of detecting differences among progeny and between progeny and parental responses. Reciprocal crosses were made between inbred lines 52 and 65, and between 70 and 73. For each pair, two types of descendents were generated: Type I was from high-line females mating with low-line males; and Type II was from low-line females mating with high-line males. The Type I and II descendents were maintained in a jar in a climate chamber under conditions described above for maintenance of the inbred lines. It took about one to two generations $\left(F_{1}\right.$ and $\left.F_{2}\right)$ for the populations to build up sufficient numbers for testing. Subsequently, comparisons among the progeny and both parents were made. Consumption and oviposition rates of both parental lines and both types of progeny for the second pair (70 vs 73) were also examined using the methods described above. On average, 30 young adult females were examined for each line. Patch location efficiency of predatory mite lines was also tested based on the protocol described above.

\section{Estimates of heritability}

Isofemale lines can be regarded as full-sib families. Heritability for the traits related to the olfactory response of inbred isofemale lines was estimated from the mean square (MS) between groups; MS within groups are decreased by a factor of $1 / x$ where $x$ represents the group size (Becker, 1984). Thus, the inbred isofemale heritability for measurements on groups can be defined as:

Isofemale heritability $\left(\mathrm{h}^{2}\right)=2 \sigma_{\mathrm{g}} /\left(\sigma_{\mathrm{S}}^{2}+\sigma_{\mathrm{w}}{ }^{2}\right)$

and standard error SE $\left(\mathrm{h}^{2}\right)=$

$2 \sqrt{ }\left(\left(2(n-1)(1-t)^{2}\left(1+\left(K_{1}-1\right) t\right)^{2}\right) /\left(K_{1}^{2}(n-s)(s-1)\right)\right)$,

where $K_{1}=\left(n-\Sigma n_{i}^{2} / n\right) /(s-1)$.

Here $\sigma_{\mathrm{S}}{ }^{2}$ and $\sigma_{\mathrm{w}}{ }^{2}$ are estimates of the $\frac{1}{4}$ of the additive genetic variance and remainder of the genetic variance plus all the environmental variance respectively; $t$ is intraclass correlation, $\mathrm{s}$ is the number of lines tested, $\mathrm{n}_{\mathrm{i}}$ is the number of individuals with the $\mathrm{i}$-th line, and $\mathrm{n}$ represents the total number of individuals (Becker, 1984).

\section{Results}

Inbred lines

Consumption and oviposition rate: Among the 16 inbred lines examined, certain lines consumed more prey eggs than other lines within a 24-h test interval $(P<0.001, \mathrm{~F}=$ 11.66, d.f. $=15 / 605$, ANOVA) (Figure 1a). The maximum number of prey eggs consumed by a single individual female in $24 \mathrm{~h}$ was 45 , and the minimum number was 15. On average, one adult female predator consumed 24 one-day old eggs in a 24 -h period. Predatory mites also displayed phenotypic variation in oviposition $(P<0.001$, $\mathrm{F}=4.34$, d.f. $=15 / 605$, ANOVA) (Figure 1b). Certain lines laid four eggs on average whereas some lines just laid two or even one egg in the 24-h test interval. Across all lines, oviposition of predatory mites was found to be positively correlated with consumption rate on the leaf discs $(r=0.38, P=0.02)$; mites that consumed more prey eggs laid more eggs. However, the relationship (slope)
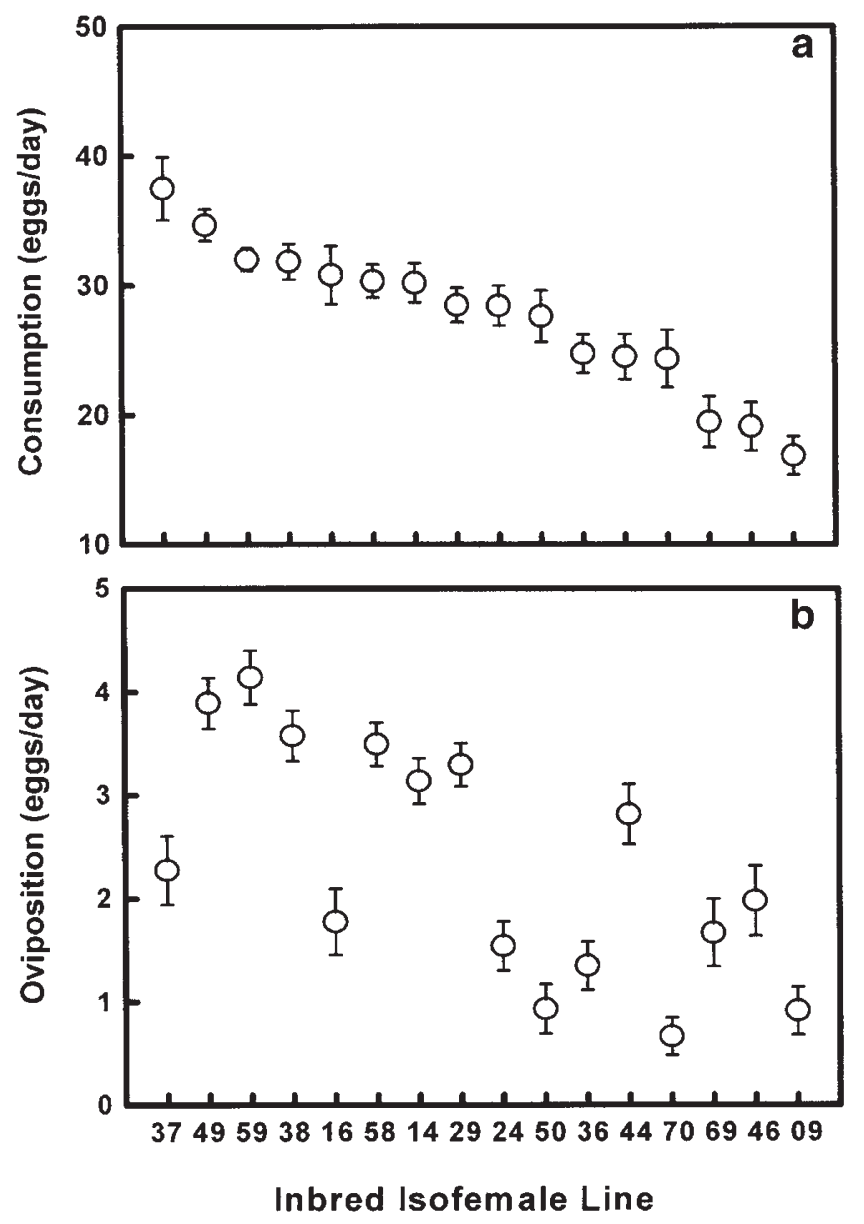

Figure 1 For each inbred line tested on leaf discs (a) mean number $( \pm \mathrm{SE})$ of prey eggs (Tetranychus urticae) consumed by female Phytoseiulus persimilis and (b) mean number $( \pm S E)$ of predator eggs laid by female $P$. persimilis within a $24-\mathrm{h}$ period. Lines ordered by decreasing consumption.

between oviposition and consumption within a line varied among lines (Table 1). Among the 16 inbred lines examined, 12 lines showed a significant correlation between consumption rate and oviposition rate $(P=$ 0.028); the range for the correlation coefficient was from 0.07 to 0.74 . However, the slopes varied considerably even where the correlation was significant, the maximum slope was 0.143 , whereas the smallest was 0.054 , indicating certain lines may convert food (prey eggs) into predatory eggs more efficiently than others. The heritability of consumption rate and oviposition rate were estimated as $0.88 \pm 0.09$ and $0.18 \pm 0.04$, respectively.

Patch residence: Significant variation in residency was detected among the 18 lines examined in the wind-tunnel in the presence of external herbivore-induced chemical volatiles, i.e. infested plants in the upwind position $(P=$ $0.001, \mathrm{~F}=2.45$, d.f. $=17 / 235$, ANOVA). Certain inbred lines stayed longer on the lima bean leaf than did others under these conditions. The average residence index was 33.0 ( \pm 7.5$)$. Lines 38 and 70 exhibited the extreme high and low responses, which were residence indices of 44.0 and 27.0, respectively (Figure 2a). In the control, in which only clean bean plants were presented in the upwind position, there was no difference ( $P=0.18$, F-test) in the 
Table 1 Variation in relationship (slope) between consumption and oviposition by inbred lines of Phytoseiulus persimilis on preyinfested leaf discs. The relationship (slope) of consumption rate and oviposition rate of each of the 16 inbred lines was estimated separately ( $t$-test for slope least-squares regression)

\begin{tabular}{rrrrr}
\hline Line & No. & Slope $^{*}$ & P-value & $R$ \\
\hline 9 & 50 & 0.069 & 0.001 & 0.200 \\
14 & 112 & 0.118 & 0.000 & 0.670 \\
16 & 50 & 0.014 & 0.500 & 0.010 \\
24 & 73 & 0.039 & 0.028 & 0.070 \\
29 & 111 & 0.128 & 0.000 & 0.680 \\
36 & 68 & 0.054 & 0.005 & 0.120 \\
37 & 47 & -0.004 & 0.860 & 0.001 \\
38 & 70 & 0.127 & 0.000 & 0.520 \\
44 & 73 & 0.143 & 0.000 & 0.740 \\
46 & 48 & 0.089 & 0.000 & 0.240 \\
49 & 49 & 0.076 & 0.008 & 0.140 \\
50 & 52 & 0.01 & 0.559 & 0.010 \\
58 & 94 & 0.119 & 0.000 & 0.520 \\
59 & 30 & 0.136 & 0.012 & 0.200 \\
69 & 42 & 0.089 & 0.000 & 0.280 \\
70 & 56 & 0.005 & 0.643 & 0.004 \\
\hline
\end{tabular}

*The relationship (slope) of consumption rate $v$ s oviposition rate of 16 inbred lines of predatory mites was estimated separately ( $t$-test for slope least-squares regression).

residence index among the eight lines examined. The average residence index was 42.0 ( \pm 3.9$)$, which, as expected, is higher than the mean residence index in the presence of herbivore-induced plant volatiles $(P=0.01$, $\mathrm{F}=8.00$, d.f. $=1 / 26$, ANOVA) (Figure 2a).

The 18 lines examined also exhibited phenotypic variation $(P=0.001, \mathrm{~F}=2.43$, d.f. $=17 / 235$, ANOVA $)$ in consumption rate (Figure $2 \mathrm{~b}$ ). Certain lines consumed more prey eggs than others within the 4-h test period. However, there were, on average, two eggs left (out of 20 eggs) on the leaf at the end of the 4-h experiment. In the presence of upwind volatiles, the length of residency was negatively correlated with consumption rate $(r=$ $=.59, P<0.001$ ) (Figure $2 \mathrm{c}$ ); those mite lines that consumed more prey eggs tended to leave sooner. We did not detect any significant difference in consumption among the lines in the control condition.

Patch location: Following release, predatory mites quickly dispersed over the whole arena. They rarely moved directly toward the disc at the center of the arena, but instead typically followed a circuitous path, suggesting there was no direct attraction. The incidence of predatory mites trapped in the sticky materials or escaping was quite low $(<10 \%)$. Of those that reached the leaf disc, it took from $15 \mathrm{sec}$ to $10 \mathrm{~min}$ to locate the disc at the center of a $40-\mathrm{cm}$ diameter arena; the average time was about 3.5 mins. On average, $40 \%$ of the predatory mites were able to reach the leaf disc within the first $10 \mathrm{~min}$, and most of those $(75 \%)$ located the leaf disc in the first 5 mins. There was no difference in the average time to reach disc among lines (Figure $3 b$ ). However, among lines that located the central disc in the first $10 \mathrm{~min}$, there was significant variation $(P<0.001, \mathrm{~F}=5.46$, d.f. $=$ $10 / 233$, ANOVA) in the proportion of mites locating the patch (Figure 3a). Certain inbred lines had a higher proportion of mites reaching the central leaf disc than did other lines. Most (95\%) predatory mites that reached the

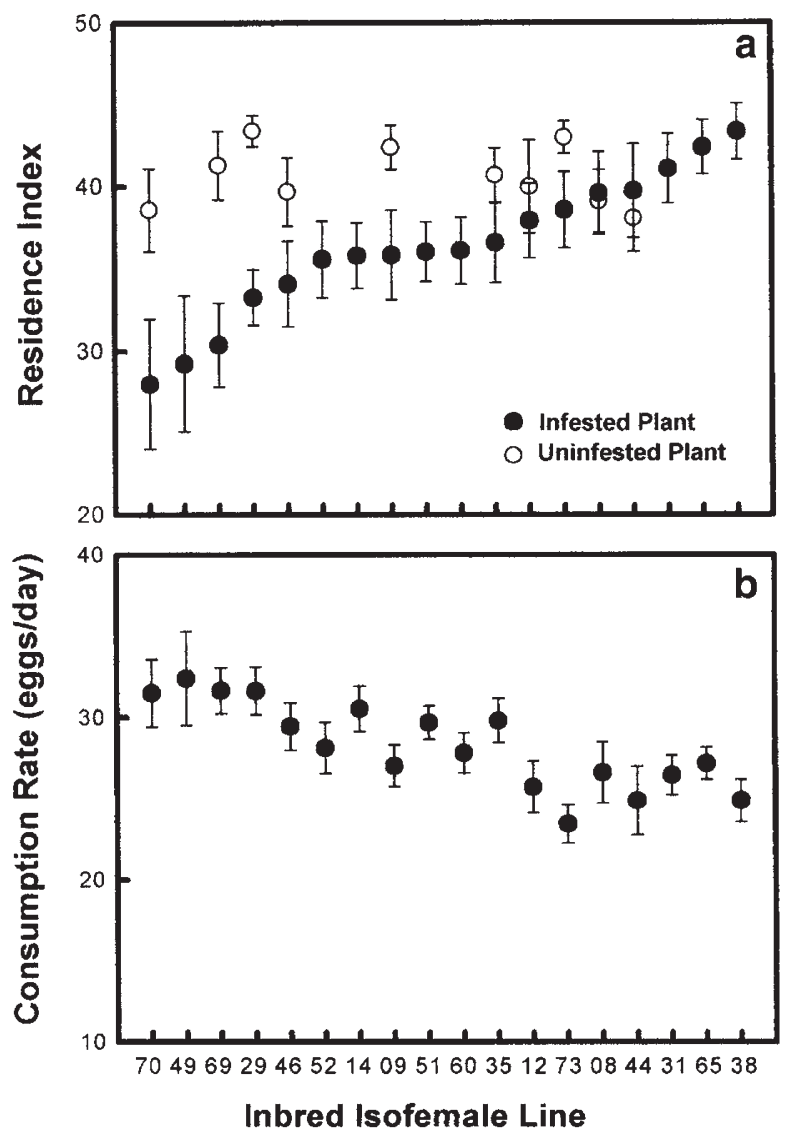

375

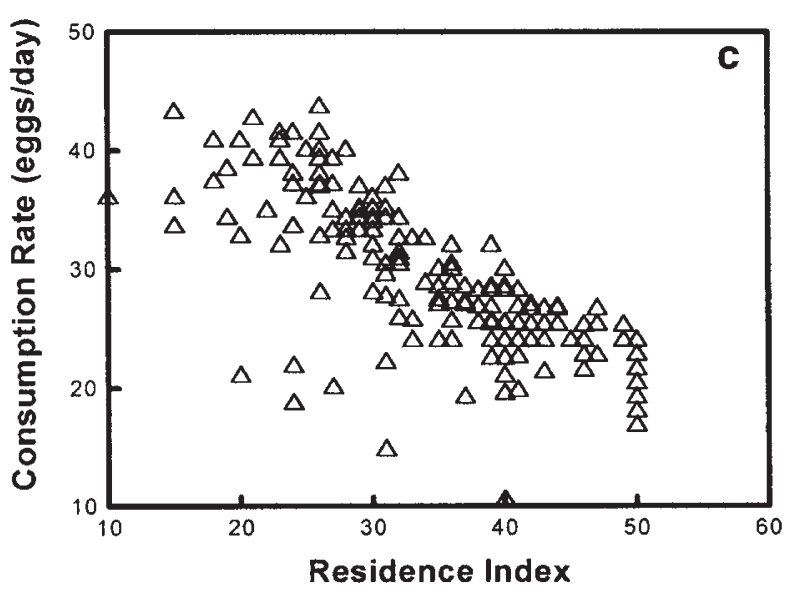

Figure 2 For each inbred line tested in wind-tunnel tests (a) mean $( \pm S E)$ patch residence index per test plant (see the definition in Materials and methods), (b) mean ( $\pm S E$ ) number of prey eggs consumed per test plant (maximum five predators for $4 \mathrm{~h}$ ), and (c) correlation of consumption and residence index. Solid circles in (a) indicate mean residence index $( \pm S E)$ of adult female Phytoseiulus persimilis with prey-infested plants upwind, empty circles with uninfested (control) plants upwind. Consumption (b) was measured in the presence of prey-infested upwind. Regression of consumption rate on residence index $(\mathbf{c}), r^{2}=0.59, P<0.001$ ( $t$-test for slope least-squares regression). Lines ordered by increasing residence index. 

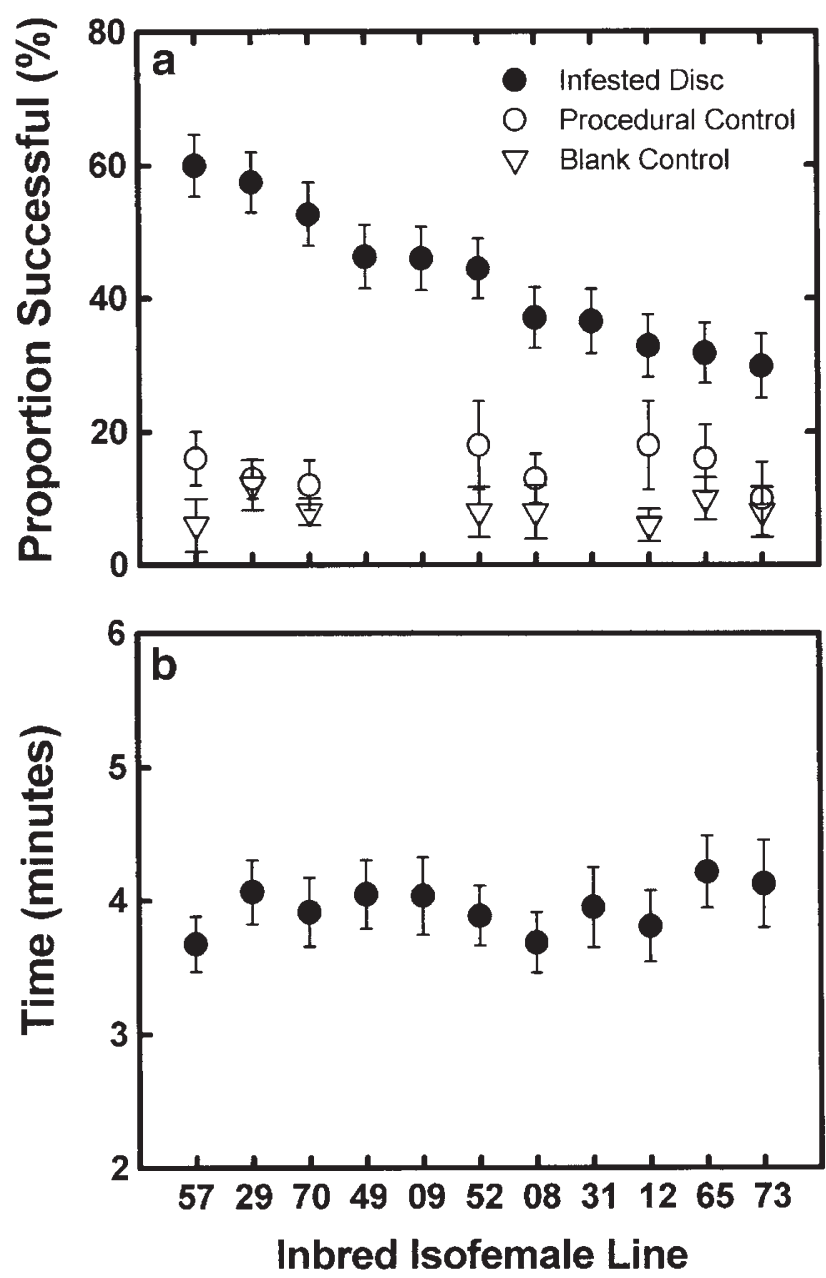

Figure 3 For each inbred line tested in the still-air arena (a) mean proportion $( \pm \mathrm{SE})$ of Phytoseiulus persimilis reaching the central leaf disc within a 10-min test interval, and (b) mean time (minutes, \pm SE) taken by predatory mites to reach a central leaf disc infested by prey mites (Tetranychus urticae). In (a), solid circles indicate the proportion that reached a disc infested by prey mites (T. urticae); empty circles indicate the proportion that reached an uninfested disc (procedural control); empty triangles indicate the proportion that reached the central area without prey or leaf disc present (blank control). Lines ordered by decreasing proportion successful.

central leaf disc remained on the disc for the remaining of the test period $(10 \mathrm{mins})$. The correlation coefficient between the number of mites that reached the disc and the number of mites that stayed on the disc at the end of experiment was 0.95 .

In the procedural control, where predatory mites were presented with a leaf disc that was not infested by mites, there was no difference among the lines (Figure 3a). The average proportion of predatory mites that arrived at the disc was $15 \%$, which was lower than the proportion that did so when the central leaf disc was infested by techanychid mites $(P<0.001, \mathrm{~F}=110.52$, d.f. $=1 / 18$, ANOVA $)$. In the blank control, with no leaf disc and no wet cotton in the center of arena, again there was no difference among lines $(P=0.69, \mathrm{~F}=0.68$, d.f. $=7 / 42$, ANOVA $)$. However, the average proportion of predatory mites that reached the disc was $9 \%$, less than the proportion doing so in the procedural control $(P=0.012, \mathrm{~F}=6.63$, d.f. $=$ $1 / 15$, ANOVA). This suggests that the clean (uninfested) disc and wet cotton may themselves be somewhat attractive to the predators, possibly due to the water vapor associated with them. The possibility that the mechanically damaged leaves released volatiles that attracted predators was specifically tested and rejected in Y-tube experiments by Dicke et al (1990b).

For the 10 lines tested both in the wind-tunnel and stillair arena, patch location was negatively correlated with residence index in the wind-tunnel $(r=-0.45, P=0.01)$. That is, those mites that had low residence index in the wind-tunnel were more likely to locate the central leaf disc on the arena (Figure 4), and vice versa.

\section{Crosses}

Consumption and oviposition rate: Two parental lines (70 and 73) differed in both consumption rate $(P=0.016, \mathrm{~F}$ $=6.08$, d.f. $=1 / 78$, ANOVA) (Figure $5 \mathrm{~b}$ ) and oviposition rate $(P=0.012, \mathrm{~F}=6.68$, d.f. $=1 / 78$, ANOVA) (Figure 5c). Line 73 consumed significantly more prey eggs than line 70 within the 24-h test interval (Figure 5b). The maximum number of prey eggs consumed by a single individual female (line 73) was 45 , and the minimum number (line 70) was 15 . On average, one adult female predator consumed 24 one-day old eggs in a 24 -h period. Line 73 laid 3.6 eggs on average whereas line 70 laid only 2.8 eggs in the 24-h interval tested. Progeny types showed no difference in either consumption rate or oviposition rate from each other. However, they consumed more prey eggs and produced more eggs than either parental line (Figure 5b, 5c). Within $24 \mathrm{~h}$, the maximum number of eggs consumed was 46 and the maximum numbers of eggs laid was seven. They consumed, on average, 35 prey eggs within $24 \mathrm{~h}$.

Olfactory response: Parental lines 52 and 65 remained different in patch location ability $(P<0.001, \mathrm{t}=6.11$, d.f. $=22.5$ ) (Figure $5 \mathrm{~d}$ ), but, there was no difference between

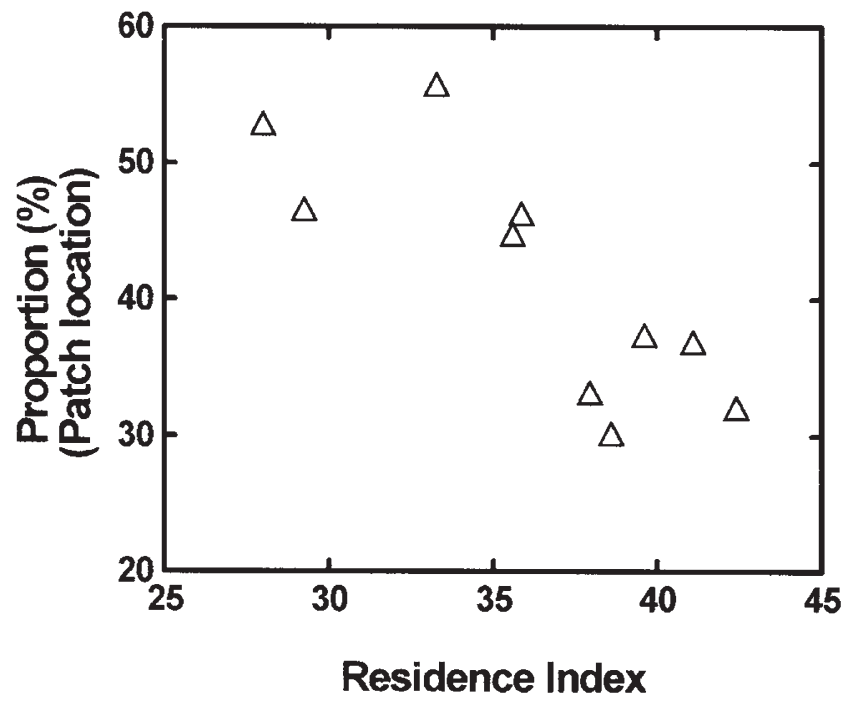

Figure 4 For each inbred line, relationship of patch location (mean proportion of predatory mites reaching the central leaf disc infested with Tetranychus urticae) and patch residency (mean residence index of predatory mites measured in a wind-tunnel) of adult female Phytoseiulus persimilis; $r^{2}=0.45, P=0.006$ ( $t$-test for slope leastsquares regression). 

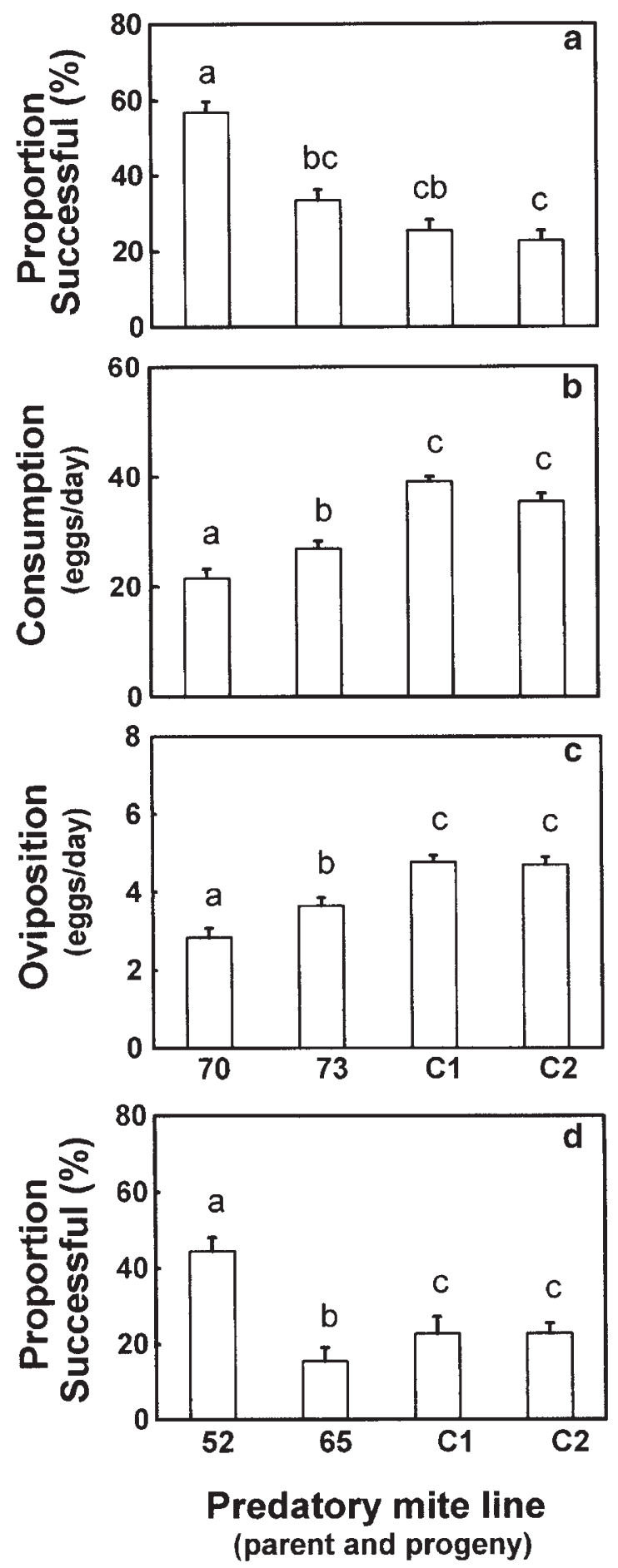

Figure 5 Crossing experiments. For crosses between lines 70 and 73 (see details of crossing procedures in Materials and methods): (a) patch location, (b) prey consumption, and (c) oviposition of two parental lines and their two types of offspring (C1 and C2). For crosses between lines 52 and 65, (d) patch location of two parental lines and their two types of offspring (C1, C2). Bars in (a) and (d) indicate mean proportion $( \pm S E)$ of predatory mites that reached a central leaf disc infested with Tetranychus urticae in a 10-min interval. Bars in (b) indicate mean number ( \pm SE) of prey eggs consumed by a predatory mite on infested disc during a 24-h period. Bars in (c) indicate mean number $( \pm S E)$ of predator eggs laid by a female predatory mite on prey-infested disc during a $24-\mathrm{h}$ period. the two types of progeny in patch location proportion

(Figure $5 \mathrm{~d}$ ). On average, about $35 \%$ of them were able to reach the disc. However, the two types of progeny were significantly different from their parents in patch location; they were more likely to reach the disc than one parent (line 65, low-line), but less likely to reach the disc than their other parent (line 52, high-line). They did not display any differences from their parents in the time needed to reach the central leaf disk $(P=0.62, \mathrm{~F}=0.24$, d.f. $=3 / 56$ ), taking about 3.5 mins for them to reach the disc.

Our data structure allowed us to perform only a partial scaling test (Kearsey and Pooni, 1996). However, certain important genetic information about the traits of interest can be derived from the results of our crossing experiments. There was no difference between the two types of progeny from either cross, suggesting that maternal influence on the traits can be excluded. The difference between the two parental lines indicates that there may be an additive genetic component. The progeny differed significantly from both parents, indicating a dominance component in determining the traits. A partial scaling test demonstrated that the additive component of patch location was [a] $=(\mathrm{p} 1-\mathrm{p} 2) / 2=0.122$, and the dominance component was $[\mathrm{d}]=\mathrm{F} 1-\mathrm{m}=-0.017$. The negative value obtained for potence ratio [d/a $=-0.143$ ] suggested a possible partial dominance of one parent (Line 52) in determining the traits.

Similar to the first pair, both parental lines from the second pair of lines (70 and 73) differed in patch location ability $(P<0.001, \mathrm{t}=6.07$, d.f. $=22.2)$, but the two types of progeny did not show any difference in either patch location proportion (Figure 5a) or patch location time. Both types of progeny seemed to be less likely to reach the central leaf disc than their two parents. On average, approximately $24 \%$ of predatory mites were able to reach the central leaf disc within the 10-min test, which was less than the mean of their parents $(45 \% ; P<0.05$, F-test). However, they did not show any differences from their parents in patch location time $(P>0.15, \mathrm{~F}$-test). It took, on average, about $4.5 \mathrm{~min}$ for them to reach the leaf disc. The partial scaling test indicated that there was an additive genetic component $([a]=(p 1-p 2) / 2=0.117)$, and dominance component ([d] $=\mathrm{F} 1-\mathrm{m}=-0.211)$ for the patch location proportion. The potence ratio $([\mathrm{d} / \mathrm{a}]=$ -1.81) was again a negative value.

\section{Discussion}

Our experiments demonstrate that there is a genetic component in the olfactory response of $P$. persimilis to herbivore-induced plant volatiles, confirming earlier findings from olfactometer experiments (Margolies et al, 1997). In both wind-tunnel and patch location experiments, the inbred isofemale lines showed significant among-line variation in the presence of prey or preyrelated cues, but no difference in the absence of such cues. The inbred isofemale lines that we used were established in the laboratory for more than 10 generations prior to testing, therefore more than $80 \%$ of the loci may have become homozygous (Falconer, 1983). Because inbreeding redistributes the total genetic variance in a population such that the genetic variance appears in the between-line component (Falconer, 1983), our results indicate that much of the variation among lines can be 
attributed to genetic differences in response to the volatiles. Furthermore, the partitioned estimate of variation among isofemale lines is an estimate of the total genetic variation in the population (Rockwell et al, 1975). Information drawn from our line-cross experiments confirms the presence of additive genetic variance in response to herbivore-induced plant volatiles, and it was found to be heritable. However, in the first pair (52 vs 65) of line-cross comparison, the two types of progeny were between their two parents in patch location, whereas in the second pair (70 vs 73), the progeny were less than their two parents in patch location, suggesting that a simple additivedominance model may not be appropriate. In reality, the genetic architecture of response to herbivore-induced plant volatiles by predatory mites could be much more complicated.

One concern about this interpretation is that nongenetic maternal effects may have contributed to the difference among lines. However, the line-cross experiments demonstrated that the two types of progeny from the reciprocal matings did not differ in patch location, suggesting that cytoplasmic maternal effects could be ruled out. Although we found no evidence of maternal effects, it is difficult to draw any stronger conclusions in the absence of a larger set of crosses. Another possible confounding factor was the effect of certain contagious diseases and protozoan (microsporidian) pathogens on foraging behavior of predatory mites (Bjornson and Keddie, 1999; Schutte et al, 1998). Infection of some, but not all, lines could have resulted in the type of differences we found. However, when we tested eight isofemale lines that showed widely different responses in our experiments they were free of microsporidian infection (S Bjornson, personal communication). Therefore, the difference we found among lines is likely not attributable to the influence of microsporidian.

The negative relationship between patch residence index and patch location proportion that we found was also suggested by Margolies et al (1997), and may reflect an incidental trade-off among search behaviors. The effects of this trade-off may be compounded by phenotypic correlation between residence and consumption. Moreover, because patch location ability of $P$. persimilis was negatively correlated with patch residency, patch location by predatory mites should also be negatively correlated with consumption. We found support for this in one line-cross (70 vs 73), in which both types of progeny exhibited higher consumption rates and lower patch location abilities than either of their parental lines. The consequence of these relationships among traits is that predatory mites in lines that respond strongly to herbivore-induced bean volatiles may be more likely to be attracted to a neighboring prey patch and spend more time in searching than feeding. In contrast, predatory mites from lines having a high residence index may be less likely to be attracted to a neighboring prey patch and spend relatively more time handling and consuming prey. In addition, because residence time in the presence of an external volatile source is positively correlated (at least phenotypically) with oviposition as well as consumption, the former may also leave fewer offspring in a patch than the latter, resulting in lower predator population growth in a local patch. Overall, then, predators with a strong olfactory response would seem to be less efficient in exploiting a local prey patch than those with a weaker response.

However, the existence of genetic variation and tradeoffs among these foraging traits of predatory mites suggests that predatory mites must be able to adopt different foraging strategies in a tritrophic system. Phytoseiulus persimilis must deal with the potential conflicts that arise in allocating time and energy to different foraging demands, especially when resources become scarce. In tritrophic systems in which herbivores-induced plant volatiles attract natural enemies of tetranychid mites, natural selection might be expected to favor predator genotypes that employ plant volatiles more effectively to find and exploit their prey. That is, predatory mites that are more sensitive to chemical volatiles are more likely to efficiently locate new prey patches and may be at a selective advantage, especially when food becomes scarce. Although selection imposed on a population in nature is usually far from obvious, in the absence of other forces the additive genetic variance of foraging behaviors in predatory mites is expected to be reduced over time. Thus, finding a substantial amount of genetic variation in foraging behaviors of predatory mites is in conflict with this expectation, suggesting that the selection may be not directional or consistent. The advantage of certain genotype responses to herbivore-induced plant volatiles may be offset by the low consumption rate and low oviposition rate, whereas those genotypes with high oviposition rate may be able to offset the negative influence of weak odor sensitivity and high mortality at early age. In this way, natural selection imposed on the population may vary spatially and temporally and both genotypes may have similar fitness in nature. It is also possible that variation of plant production of attractive volatiles, which may be influenced by variation in prey numbers as well as by phenotypic variability of the plants, may contribute to the natural variation in predator response.

Our results also have practical implications as well as the ecological and evolutionary ones. Increasing the efficiency of natural enemies is a key concern in biological control (Lewis and Nordlund, 1985). Good searching ability is an important component of successful control of pests by natural enemies (van Lenteren and Woets, 1988), and predators that use prey-related plant signals to search for prey may be more effective at locating prey patches (Rosen and Huffaker, 1983), especially over a relatively long distance. With this in mind, several scientists have proposed breeding plants that produce higher levels of prey-induced plant volatiles to attract natural enemies to infested plants (Dicke et al, 1990a; Lewis and Martin, 1990; Vet and Dicke, 1992). Our results suggest that, to the same end, it should be possible to breed natural enemies, at least $P$. persimilis, to be more responsive to prey-induced plant volatiles. However, our results also indicate that heightening predator response to plant volatiles may lead to diminished control of a local pest population if predators disperse more readily. We do not yet know how genetic variation in olfactory response and correlated foraging traits influences predator search efficiency and predator-prey population dynamics. These questions remain to be answered to understand the role of plant volatiles and predator response in nature. 


\section{Acknowledgements}

We thank Dr James Campbell, Dr James Nechols, and Dr Alberto Broce for their valuable comments on an earlier version of the manuscript and two anonymous referees whose criticisms led to improvement of the paper. This is Contribution No. 02-221-J from the Kansas Agricultural Experiment Station, Kansas State University, Manhat$\tan , \mathrm{KS}$.

\section{References}

Becker WA (1984). Manual of Quantiative Genetics, 4th edn. Academic Enterprises: Pullman, WA.

Bjornson S, Keddie BA (1999). Effect of Microsporidium phytoseiuli (Microsporidia) on the performance of the predatory mite, Phytoseiulus persimilis (Acari: Phytoseiidae). Biolog Cont 15 153-161.

Bruins EBA, Wajnberg E, Pak GA (1994). Genetic variability in the reactive distance in Trichogramma brassicae after automatic tracking of the walking path. Entomol Exp Apl 72: 297-303.

Dicke M, Sabelis MW (1988). How plants obtain predatory mites as bodyguards. Neth J Zool 38: 148-165.

Dicke M, Dabelis MW (1989). Does it pay plants to advertize for bodybuards? In: Lambers $\mathrm{H}$, Cambridge ML, Konings $\mathrm{H}$, Pons TL (eds) Causes and Consequencs of Variation in Growth Rate and the Productivity of Higher Plants, SPB Academic Publishing: The Hague. pp. 341-358.

Dicke M, Sabelis MW, Takabayashi J, Bruin J, Posthumus MA (1990a). Plant strategies of manipulating predator-prey interactions through allelochemicals: prospects for application in pest control. J Chem Ecol 16: 3091-3118.

Dicke M, Van Beek TA, Posthumus MA, Ben Doom N, Van Bokhoven H, De Groot AE (1990b). Isolationand identification of volatile kairomone that affects acarine predator-prey interactions: involvement of host plant in its production. J Chem Ecol 16: 381-396.

Falconer DS (1983). Introduction to Quantitative Genetics, 2nd edn. Longman: New York.

Falconer DS, Mackay TFC (1996). Introduction to Quantitative Genetics, 4th edn. Longman: New York.

$\mathrm{Gu} \mathrm{H}$, Dorn S (2000). Genetic variation in behavioral response to herbivore-infested plants in the parasitic wasp, Cotesia glomerata (L.) (Hymenoptera: Braconidae). J Insect Behavior 13: 141-156.

Hopper KR, Roush RT, Powell W (1993). Management of genetics of biological-control introductions. Ann Re Entomol 38 : 29-51.

Hoy MA (1990). Genetic improvement of anthropod natural enemies: becoming a conventional tactic? In: Baker RR, Dunn PE (eds) New Directions in Biological Control, Alan R. Liss Inc: New York. pp 405-417.

Janssen A (1999). Plants with spider-mite prey attract more predatory mites than clean plants under greenhouse conditions. Entomologia Experimentalis et Applicata 90: 191-198.

Kearsey MJ, Pooni HS (1996). The Genetical Analysis of Quantitative Traits. Chapman and Hall: London.

Lewis WJ, Martin Jr WR (1990). Semiochemicals for use with parasitoids: status and future. J Chem Ecol 16: 3067-3089.

Lewis WJ, Nordlund DA (1985). Behavior-modifying chemicals to enhance natural enemy effectiveness. In: Hoy MA, Herzog DC (eds) Biological Control in Agricultural IPM Systems, Academic Press: Orlando, FL. pp 89-101.

Mackauer, M (1976). Genetic problems in the production of biological control agents. Ann Rev Entomol 21: 369-383.

Maeda T, Takabayashi J, Yano S, Takafuji A (1999). Response of the predatory mite, Amblyseius womersleyi (Acari
Phytoseiidae), toward herbivore-induced plant volatiles: variation in response between two local populations. App Entomol Zoo 34: 449-454.

Mankin RW, Vick KW, Mayer MS, Coffelt JA, Callahan PS (1980). Models for dispersal of vapors inopen and confined spaces: application to sex pheromone trapping in a warehouse. I Chem Ecol 6: 929-925.

Margolies DC, Boyer Jr JE, Sabelis MW (1997). Response of a phytoseiid predator to herbivore-induced plant volatiles: selection on attaction and effecy on prey exploitation. J Insect Behav 10: 715-729.

Mayland H (1998). Effects of pre-induced plant volatiles on search behaviors of the predatory ite, Phytoseiulus persimilis. Master Thesis, Kansas State University, Manhattan, KS.

Mayland H, Margolies DC, Charlton RE (2000). Multiple preyrelated cues influence residence time of an acarine predator, Phytoseiulus persimilis, on prey host plants. Entomol Exp Apl 96: 245-252.

Parsons PA (1980). Isofemale strains and evolutionary strategies in natural populations. Evol Bio 13: 175-217.

Parsons PA (1983). The Evolutionary Biology of Colonizing Species. Cambridge University Press: Cambridge, England.

Pels B, Sabelis MW (1999). Local dynamics, overexploitation and predator dispersal in an acarine predator-prey sysem. Oikos 86: 573-583.

Price PW, Bouton CE, Gross P, McPheron BA, Thompson JN, Weis AE (1980). Interactions among three trophic levels: influence of plants on interactions between insect herbivores and natural enemies. Ann Rev Ecol Syst 11: 41-65.

Rockwell RF, Cooke F, Harmsen R (1975). Photobehavioral differentiation in natural populations of Drosophila pseudoobscura and Drosophila persimilis. Behav Genet 5: 189-202.

Rosen D, Huffaker CB (1983). An overview of desired attributes of effective viological control agents, with particular emphasis on mites. In: Hoy MA, Cunningham GL, Knutson L (eds), Biological Control of Pests by Mites, University of California: Berkeley. pp 2-11.

Sabelis MW (1981). Biological control of two-spotted spider mite using phytoseiid predators. Part I: Modelling the Predator-Prey Interaction at the Individual Level. Agricultural Research Reports 910, Pudoc, Wageningen, Netherlands. 242 pp.

Sabelis MW (1985). Reproduction and sex allocation. In: Helle W, Sabelis MW (eds) Spider Mites: Their Biology, Natural Enemies and Control Vol. 1B, Elsevier Science Publishers: Amsterdam. pp 73-94.

Sabelis MW,Van der Weel JJ (1993). Anemotactic responses of the predatory mites, Phytoseiulus persimilis Athias-Henriot, and their role in prey finding. Exp Appl Acarol 17: 521-529.

Sabelis MW, Vermaat JE, Groeneveld A (1984). Arrestment responses of the predatory mite, Phytoseiulus persimilis, to steep odour gradients of kariomones. Physiol Entomol 9: 437-446.

Schutte C, Van Baarlen P, Dijkman H, Dicke M (1998). Change in foraging behaviour of the predatory mice Phytoseiulus persimilis after exposure to dead conspecifics and their products. Entomol Exp Appl 88: 295-300.

Van Baalen M, Sabelis MW (1995). The milker-killer dilemma in spatially structured predator-prey interactions. Oikos 74: 391-400.

Van Lenteren JC, Woets J (1988). Biological and integrated pest control in greenhouses. Am Rev Entomol 33: 239-269.

Vet LEM, Dicke M (1992). Ecology of infochemical use by natural enemies in a tritrophic context. Ann Rev Entomol 37: 141-172.

Zemek R, Nachman G (1998). Interactions in a tritrophic acarine predator-prey metapopulation system: prey location and distance moved by Phytoseiulus persimilis (Acarina: Phytoseiidae). Exp Appl Acarol 22: 259-278. 